\title{
Las minas de Rodalquilar
}

\author{
Francisco Hernández Ortiz | geólogo \\ URL de la contribución <www.iaph.es/revistaph/index.php/revistaph/article/view/4004>
}

\section{RESUMEN}

En el área de Rodalquilar existen unos yacimientos minerales que han sido explotados económicamente desde hace tiempo. Por la minería de Rodalquilar han pasado pequeñas empresas locales, empresas nacionales tanto privadas como públicas, multinacionales mineras e incluso la Corona de España en el siglo XVI, alternándose ciclos de gran actividad con otros de baja, todo ello motivado por diferentes factores políticos, militares, económicos, sociales e incluso especulativos.

La importancia de sus minas ha variado con el paso del tiempo; desde jugar un papel estratégico destacado en el mercado de los alumbres europeos en el siglo XVI, hasta otro de carácter social local en la etapa de la minería pública aurífera a mediados del siglo XX.

La presencia de una rica geología económica y de una actividad minera continuada para explotarla han interactuado durante cientos de años con el medio biótico, dando como resultado final un paisaje cultural (en terminología UNESCO) que actualmente se encuentra reconocido mediante diferentes figuras. A nivel nacional, con la declaración del Parque Natural MarítimoTerrestre de Cabo de Gata-Níjar (1987), y con la declaración, por parte de la UNESCO, de la Reserva de la Biosfera de Cabo de Gata-Níjar (1997) y la declaración del Geoparque Europeo de Cabo de Gata-Níjar (2006), a nivel internacional. Pero aún queda por reconocer y poner en valor su destacado patrimonio minero.

\section{Palabras clave}

Almería | Alumbre | Campo de Níjar | Metalurgia | Minas (Inmueble) | Oro | Rodalquilar | 


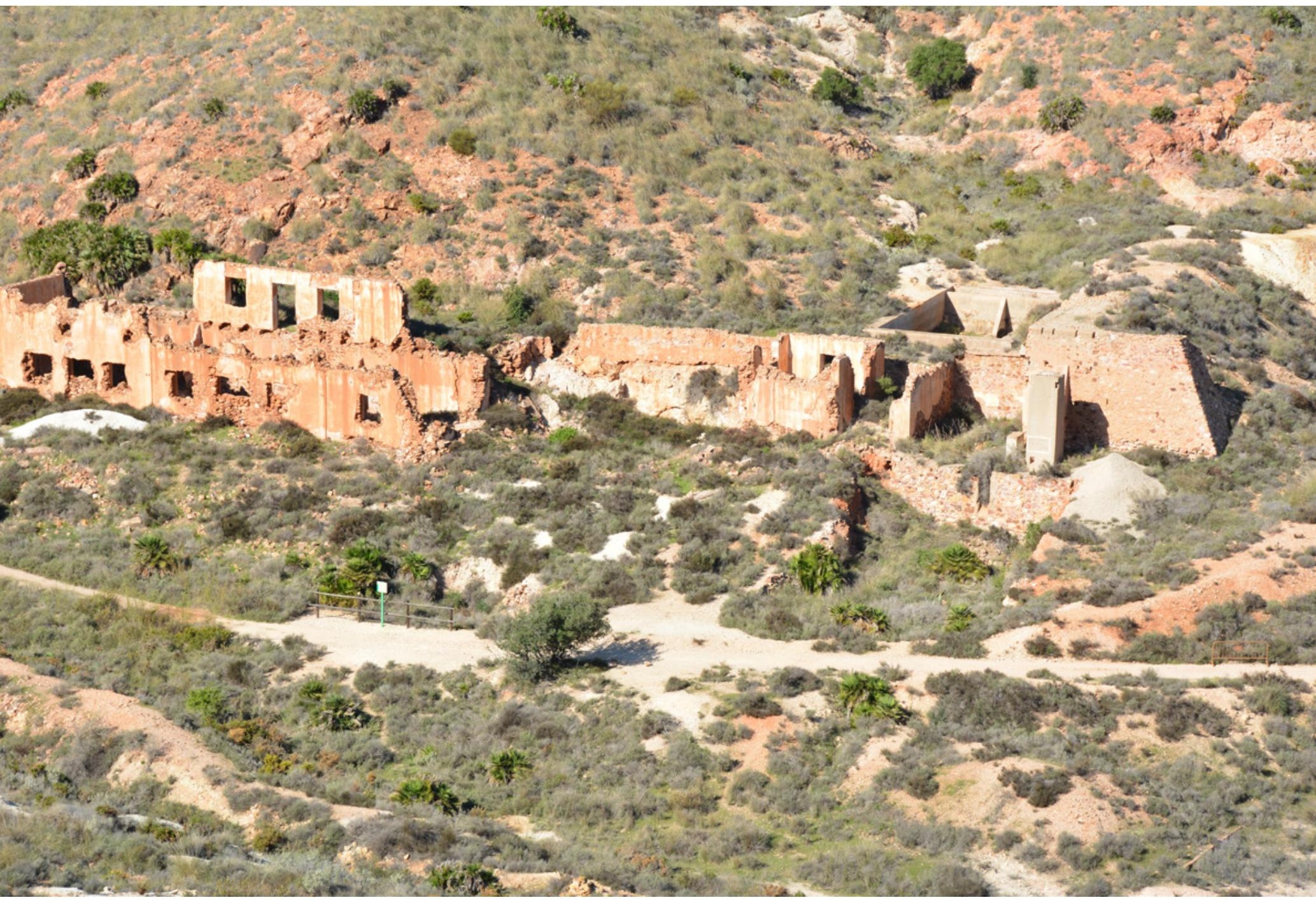

Instalación metalúrgica de amalgamación de las conocidas como Minas de Abellán levantadas bajo la tutela de Antonio Abellán Gómez en el año 1929 | foto Francisco Hernández Ortiz es autor de todas las imágenes que ilustran este artículo si no se indica lo contrario 


\section{INTRODUCCIÓN}

El pueblo de Rodalquilar se encuentra localizado geográficamente en la sierra del Cabo de Gata, en la costa del Levante de la provincia Almería, con unos 25 kilómetros de largo por unos 5 de ancho, rondando su máxima altura los 500 metros, comenzando en el faro del Cabo de Gata y llegando a las inmediaciones del faro de Mesa Roldán. Rodalquilar se encuentra localizado geológicamente en el campo volcánico del Cabo de Gata (Almería), uno de los diferentes dominios geológicos que conforman el "volcanismo neógeno del sudeste de España", el cual abarca buena parte de las provincias de Almería y Murcia (LÓPEZ RUIZ; RODRÍGUEZ BADIOLA, 1980; MARTÍN; BRAGA; BETZLER, 2003).

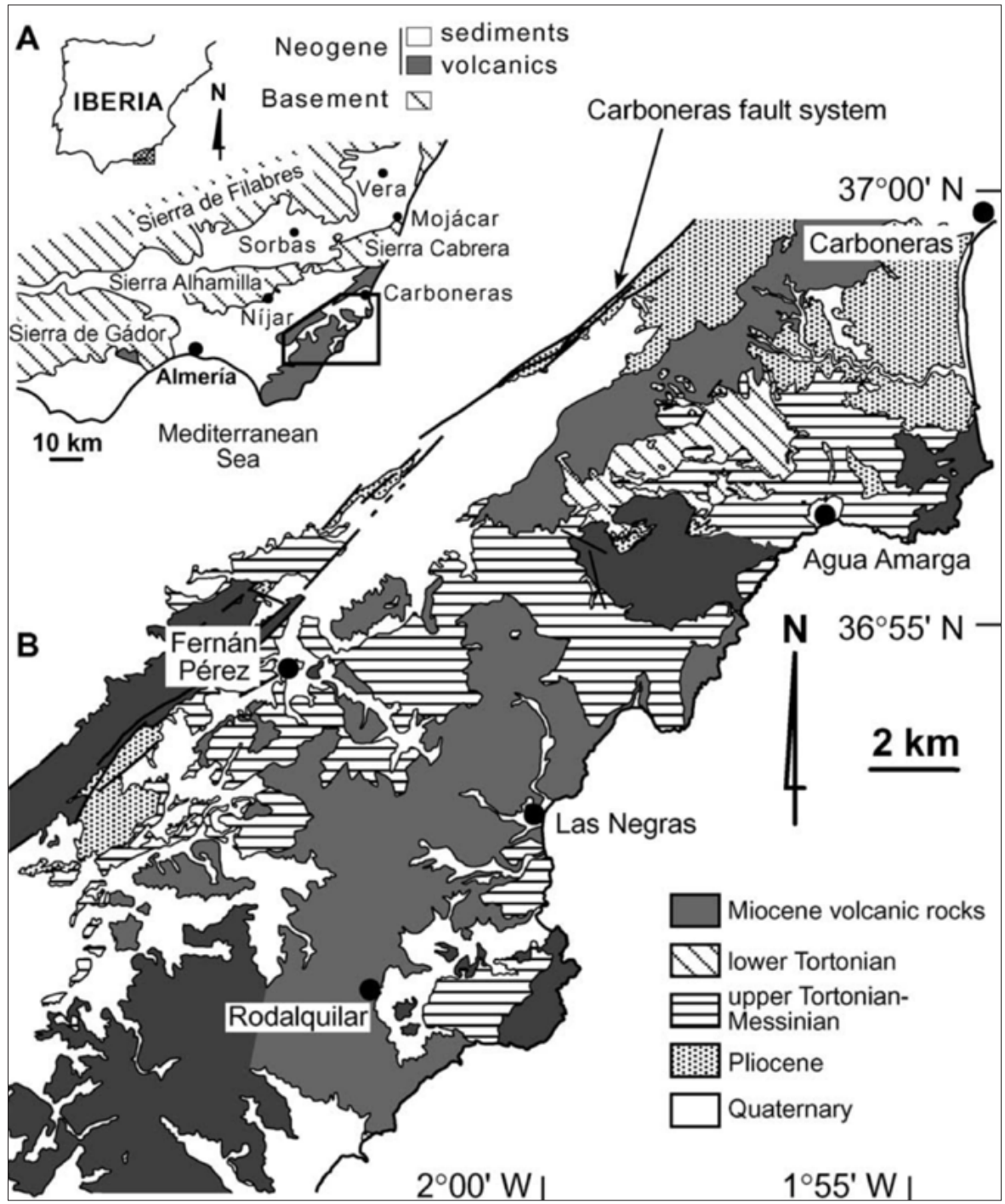




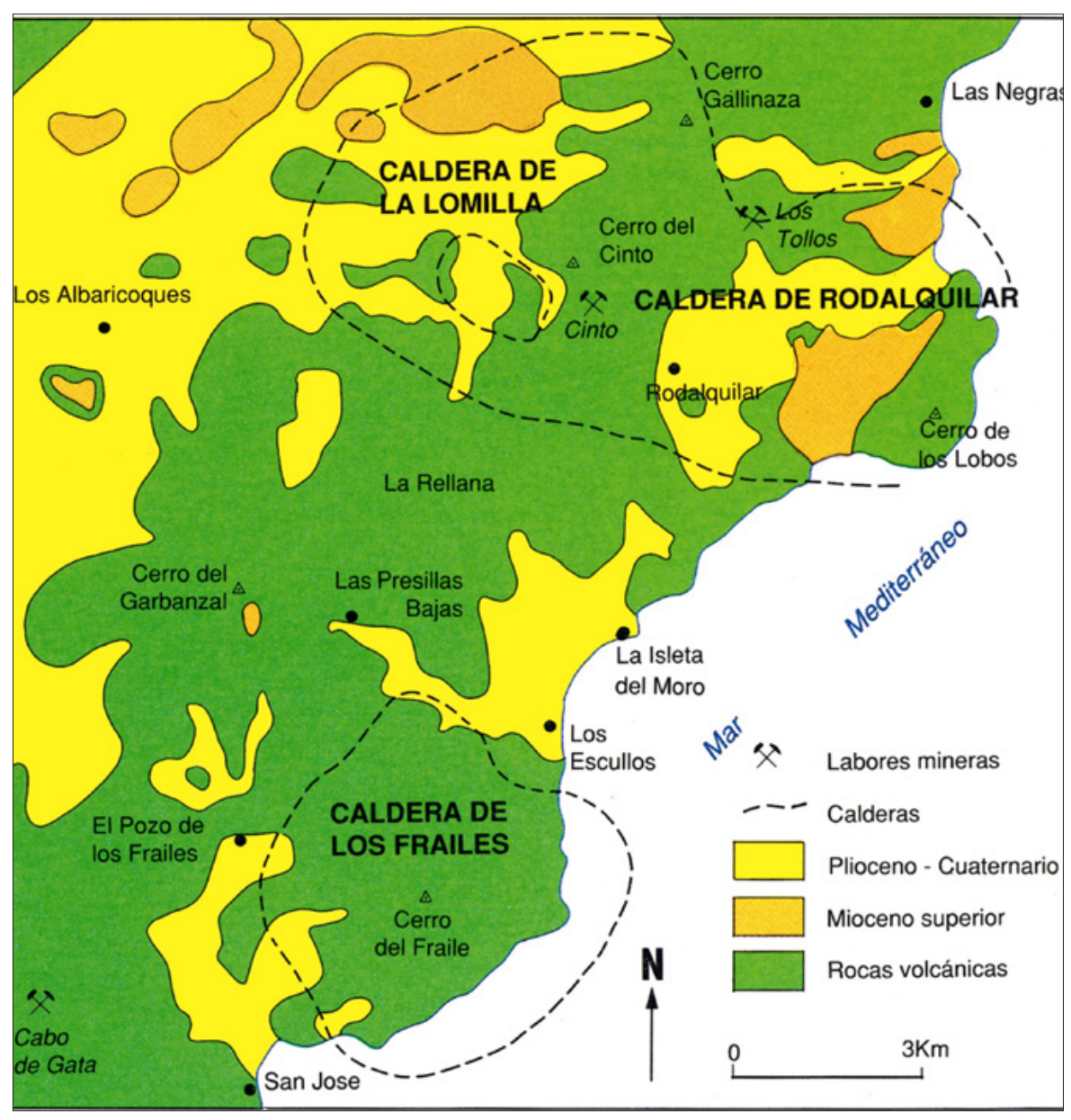

El origen de los principales yacimientos minerales que contiene el coto minero de Rodalquilar -depósitos de $\mathrm{Pb}-\mathrm{Zn}-(\mathrm{Cu}-\mathrm{Ag}-\mathrm{Au})$ y depósitos de Au-(Cu-Te-Sn)- está relacionado fundamentalmente con la creación de calderas (caldera de Rodalquilar y caldera de La Lomilla), el relleno de filones (epitermales de baja y alta sulfuración) y las alteraciones hidrotermales de sus rocas volcánicas calcoalcalinas (ARRIBAS, 1993; ARRIBAS; CUNNINGHAM; RYTUBA et ál., 1995; ARRIBAS MORENO, 1998).

Los principales metales objeto de explotación económica en la etapa contemporánea han sido el plomo, la plata y el oro (E.M.M.E. 18611996). También es de destacar las labores mineras de los alumbres de Rodalquilar durante el siglo XVI (HERNÁNDEZ ORTIZ, 2009a). Además han existido otras minerías de menor importancia, como la de los adoquines (HERNÁNDEZ ORTIZ, 2004), los caolines, las piedras semipreciosas (HERNÁNDEZ ORTIZ, 2009a: 18-19) y la de tierras refractarias (PUCHE RIART, 2002: 410).
Mapa geológico esquemático de Rodalquilar | fuente ARRIBAS, 1993 


\section{EL INICIO DE LA MINERÍA EN RODALQUILAR}

Existen multitud de hipótesis para situar el punto inicial de la minería en Rodalquilar, aunque muchas se basan más en la imaginación que en datos fiables.

A día de hoy no se dispone de pruebas determinantes sobre actividades mineras en Rodalquilar durante la Antigüedad, aunque sí que existen algunos indicios que pudiesen apuntar en esa dirección, siendo uno de ellos una necrópolis probablemente romana, descubierta por la Empresa Nacional Adaro en el año 1953 en el cerro del Cinto. La necrópolis está situada entre algunas de las zonas auríferas más ricas de toda la zona. En total aparecieron en la necrópolis nueve sepulturas de inhumación en fosa, con una profundidad media de 1 metro (ARRIBAS PALAU, 1953: 365-369).

Durante la Edad Media se continúa con las especulaciones e indicios débiles sobre alguna posible actividad minera en Rodalquilar, pero nunca van acompañados de pruebas contundentes (HERNÁNDEZ ORTIZ, 2002: 38-39).

\section{LA MINERÍA DE LOS ALUMBRES DE RODALQUILAR (1509-1592)}

Cuando las minas de alumbre de Bizancio caen en manos de los turcos a mediados del siglo $\mathrm{XV}$, se produce un encarecimiento en los precios del mercado. Dada la estrecha dependencia en la que estaba la industria textil europea respecto al alumbre asiático, la respuesta de la Europa cristiana es buscar nuevos yacimientos de alumbre, intentándolo dentro de sus fronteras geográficas (RUIZ MARTíN, 2005: 48).

Las minas de alumbre de Rodalquilar (puestas en marcha en 1509), junto con las de Mazarrón en Murcia (puestas en marcha en 1462) y las de Tolfa en Italia (puestas en marcha en 1462), jugarán un papel fundamental en el abastecimiento de alumbre a Europa desde la caída de Bizancio hasta la década de 1590 (FRANCO SILVA, 1996; RUIZ MARTÍN, 2005; MUÑOZ BUENDÍA, 2007). El principal interés del alumbre era su uso en la industria textil y radicaba en que muchos colorantes naturales formaban una combinación inestable con los tejidos, de manera que el alumbre era necesario para desgrasar los citados tejidos $y$, al mismo tiempo, hacer de elemento fijador de los colores en las telas. Esta función la desempeñaban los mordientes, cuyo principal representante era el alumbre (GUAL CAMARENA, 1976; HERNÁNDEZ ORTIZ, 2010: 36).

En marzo del año 1509 la Corona concede, mediante cédula real, al licenciado y consejero de la Reina, Francisco de Vargas, la explotación de los alumbres del Obispado de Almería, dentro del cual se encontraba Rodalquilar (GIL 




Castillo de los alumbres de Rodalquilar levantado en el año 1509

ALBARRACÍN, 1995; MUÑOZ BUENDÍA, 2007: 464-465). Inmediatamente las minas de alumbre de Rodalquilar entran en funcionamiento y se consideran como la primera actividad minera documentada en Rodalquilar.

Las minas y la fábrica de alumbres de Rodalquilar, emplazada junto al castillo de los alumbres, dieron lugar al antiguo pueblo de Rodalquilar del siglo $\mathrm{XVI}$, habitado por varios cientos de personas y situado en los alrededores del citado castillo, en lo que hoy es la barriada de La Ermita, a un escaso kilómetro de distancia del fondeadero del Playazo (GIL ALBARRACíN, 1995; HERNÁNDEZ ORTIZ, 2009a). La minería se desarrolló aquí a lo largo del siglo XVI alternándose los periodos de actividad con los de inactividad, todo ello influenciado por factores políticos, militares, económicos y mineros (MUÑOZ BUENDÍA, 2007; HERNÁNDEZ ORTIZ, 2010).

En 1592 cierran los alumbres de Rodalquilar definitivamente (RUIZ MARTíN, 2005: 232) y dejarán un patrimonio minero representado por el castillo de los alumbres, por el puerto, excavado en la roca, en donde se embarcaban 



A la izquierda, mina de alumbre o "tollo", en forma de cráter, situada en las inmediaciones de la ladera oeste del cerro de La Molata; a la derecha, mina de alumbre o "tollo", en forma de trinchera, situada en las inmediaciones de la ladera este del cerro de Cinto en la zona sur del Playazo de Rodalquilar y por las alrededor de 30 minas de alumbre que aun hoy en día se pueden ver en la caldera de Rodalquilar, tanto en las inmediaciones de la ladera oeste del cerro de la Molata, como en las inmediaciones de ladera este del cerro del Cinto (HERNANDEZ ORTIZ, 2009a: 100-109).

\section{LA MINERÍA DEL ORO DE RODALQUILAR (1883-1990)}



Fundición Santa Elisa de Mazarrón, lugar adonde habitualmente se enviaban los cuarzos auríferos de Rodalquilar para obtener su oro a finales del siglo XIX e inicios del XX | foto Mariano Guillén Riquelme
En 1864 parece ser que ya se conocía la existencia de oro en Rodalquilar, concretamente en el crestón del filón de la mina de Las Niñas (MINERÍA, 1986: 67) pero todo quedó en rumores.

Algo más tarde, en el año 1883, se divulga el descubrimiento de importantes cantidades de oro en tres muestras analizadas en laboratorio y que procedían de la mina Las Niñas en Rodalquilar (E.M.M.E., 1883; REVISTA, 1883: 459). Este fue el pistoletazo de salida de la "fiebre del oro de Rodalquilar", un fenómeno que se desarrolló fundamentalmente entre los años 1883 a 1936 y que estuvo caracterizado tanto por las dificultades metalúrgicas que entrañaba la metalurgia del oro de los yacimientos de Rodalquilar, como por el carácter especulativo de una buena parte de los mineros presentes en este coto minero (HERNÁNDEZ ORTIZ, 2008).

Entre los años 1883 a 1915, la metalurgia del oro de Rodalquilar se limitaba a enviar el cuarzo aurífero de sus minas (el oro conocido estaba diseminado en el cuarzo de las minas de galena argentífera) mediante barcos desde el embarcadero del Playazo hasta las fundiciones de plomo murcianas (Mazarrón y Cartagena) para obtener allí unas barras de plomo aurífero que luego se desaurificaban en Bélgica o Alemania. Algo demasiado complejo para ser un negocio rentable (MINERÍA, 1986: 67; E.M.M.E., 1883- 


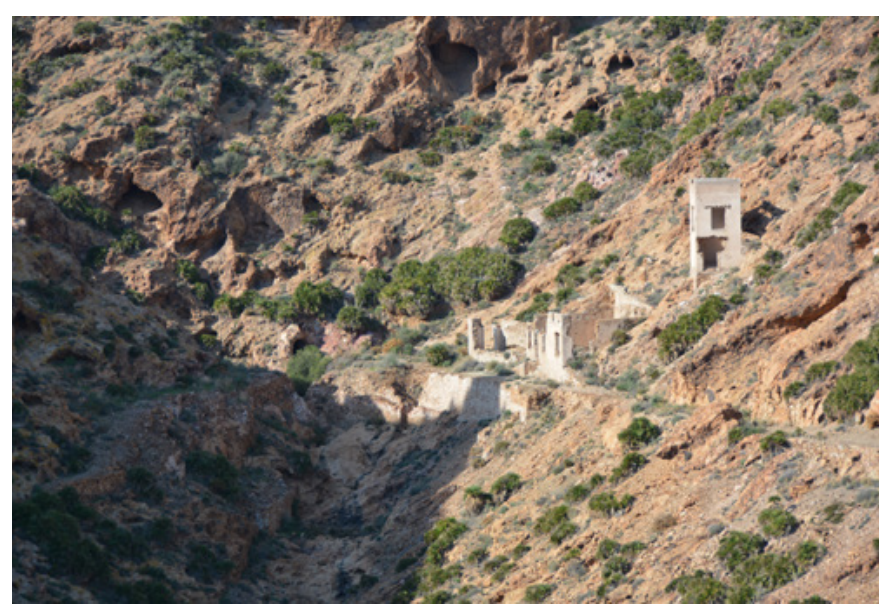

1915). No existía ni capital suficiente ni interés por parte de las pequeñas empresas mineras de Rodalquilar para construir instalaciones metalúrgicas adecuadas y a pie de mina. Las empresas se limitaban a acaparar dominio minero y esperar a ver qué ocurría. Por esta razón, el patrimonio minero de esta época es inexistente en lo que se refiere a instalaciones metalúrgicas, ya que solo había una modesta actividad extractiva, la cual sí que ha dejado un rico legado en labores mineras artesanales que muestran métodos de laboreo muy elementales. Las minas más destacadas de este periodo histórico fueron Las Niñas, Ronda y el Resto y Consulta, todas ellas situadas a apenas unos cientos de metros del casco urbano de Rodalquilar (LÓPEZ SOLER, 1940; HERNÁNDEZ ORTIZ, 2008; SÁNCHEZ PICÓN, 2015).

Entre los años 1915 y 1930 se va produciendo un cambio cualitativo y cuantitativo en las minas de oro de Rodalquilar, iniciado cuando en el año 1915 el capataz de minas Juan López Soler descubre oro en estado libre en la mina María Josefa. En esta ocasión el oro no se presentaba diseminado en el cuarzo de la mina, siendo entonces susceptible de ser extraído mediante el uso del mercurio (amalgamación), una tecnología metalúrgica asequible a los modestos presupuestos de los pequeños mineros locales de Rodalquilar. Se comienzan a gestar varios proyectos de construcción de instalaciones metalúrgicas auríferas de amalgamación a pie de mina y, tras una década, se inaugura en la mina María Josefa la primera instalación de amalgamación de Rodalquilar, liderada por Juan López Soler. Le seguirá en el año 1929 la segunda instalación de amalgamación de Rodalquilar, inaugurada en los terrenos de la mina California y liderada por Antonio Abellán. Por diferentes motivos ambas intentonas serán un fracaso tanto técnico como económico, pero dejarán los primeros restos patrimoniales contemporáneos de instalaciones metalúrgicas en Rodalquilar, aun presentes hoy en día sobre el terreno. Las minas más destacadas de este periodo histórico fueron Las Niñas, Ronda y el Resto, Consulta, Sol, Triunfo, Blanca y Negra, California
A la izquierda, instalaciones auxiliares junto a la bocamina de Las Niñas, mina en la que se descubrió oficialmente el oro de Rodalquilar en el año 1883; a la derecha instalación metalúrgica de amalgamación de la mina María Josefa, levantada bajo la tutela de Juan López Soler a mediados de la década de 1920 
y sobre todo María Josefa, que se convierte en la estrella de la minería aurífera de Rodalquilar (LÓPEZ SOLER, 1940; HERNÁNDEZ ORTIZ, 2008; 2009B; SÁNCHEZ PICÓN, 2015).

El despegue definitivo de las minas de oro de Rodalquilar se produce en el periodo 1930-1936, gracias a la llegada de capitales importantes y tecnologías adecuadas. A finales de la década de 1920 la minería de Rodalquilar atrae a los primeros inversores de peso, representados por diferentes empresas mineras. La más destacada de todas ellas fue la compañía Minas de Rodalquilar, S. A., empresa española domiciliada en Madrid, tras la cual se encontraba el Banco de Vizcaya y algunos importantes inversores europeos, así como muy destacados ingenieros de minas del ámbito internacional. Esta empresa llega a Rodalquilar en 1929 y marca el definitivo punto de inflexión alcanzando el éxito tanto técnico como económico en la minería del oro de Rodalquilar entre los años 1930 a 1936. El inicio de la Guerra Civil detiene bruscamente la actividad de esta compañía en Rodalquilar en julio de 1936, al ser intervenida por sindicalistas fieles a la Republica que se hacen cargo de sus minas e instalaciones. La herencia patrimonial dejada por Minas de Rodalquilar, S. A. es muy importante y queda plasmada tanto en la planta de cianuración Dorr, como en todas las instalaciones auxiliares y edificaciones levantadas en lo que hoy es el pueblo de Rodalquilar, el cual se puede considerar que nace en la década de 1930 gracias a la actividad desarrollada por esta empresa. Las minas más destacadas de este periodo histórico fueron Triunfo, Mi Lucia, María Josefa y sobre todo Consulta, en la cual, además

Instalación metalúrgica de cianuración, conocida como planta Dorr y levantada por la compañía Minas de Rodalquilar S. A. en el año 1930 en el pueblo de Rodalquilar | foto Oficina de Proyectos de la Escuela Técnica Superior de Ingenieros de Minas de Madrid






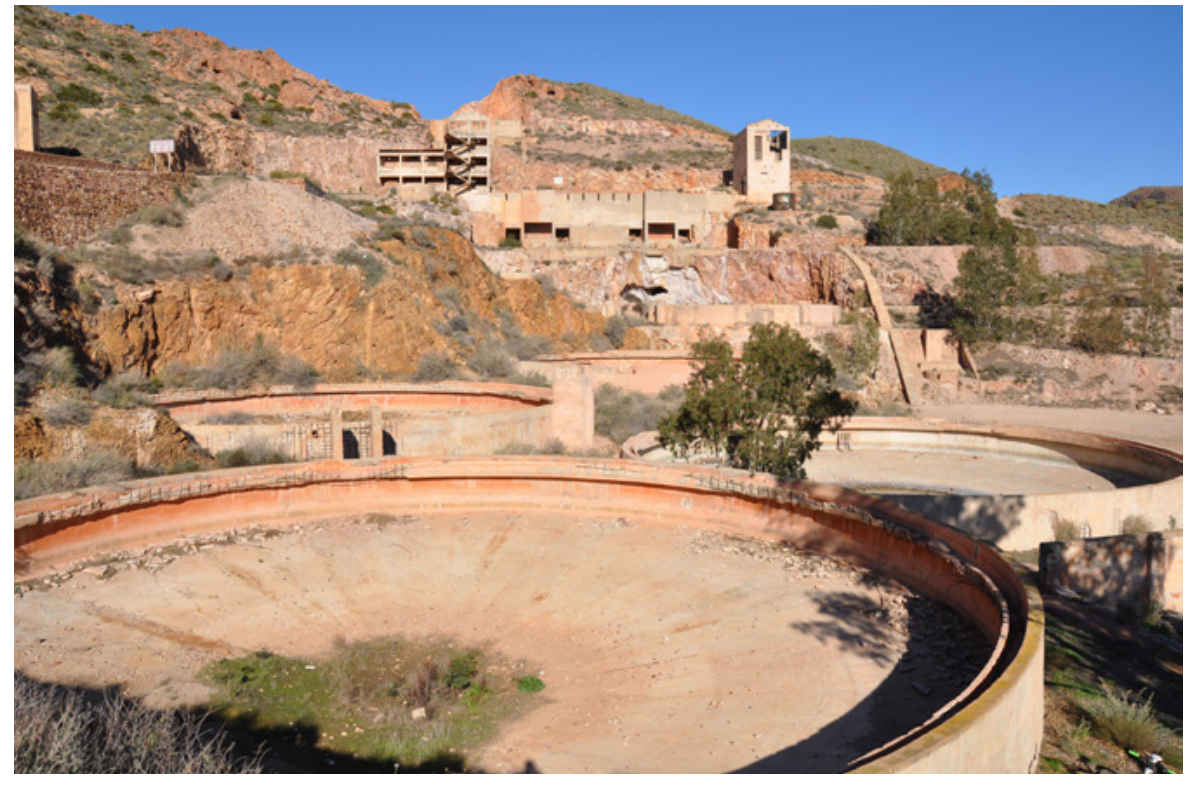

de asentarse la planta metalúrgica Dorr, también se encuentran todas sus instalaciones auxiliares (casa PAF -precipitación, Afino y Fundición-, central eléctrica, talleres mecánicos, garajes, depósito general de materiales, polvorín, oficina administrativa, casa de dirección, etc.) (LÓPEZ SOLER, 1940; HERNÁNDEZ ORTIZ, 2008; 2009b; SÁNCHEZ PICÓN, 2015).

Con la Guerra Civil llega un parón en la minería de Rodalquilar que durará hasta el año 1943, cuando la Empresa Nacional Adaro se hizo cargo de las minas de Rodalquilar por encargo del Instituto Nacional de Industria, sustituyendo al Instituto Geológico y Minero de España al frente de estas minas, el cual había tutelado las labores mineras desde su incautación en el año 1940 (HERNÁNDEZ ORTIZ, 2002: 167-169). Durante el periodo de 1936-1943, prácticamente no existe actividad minera productiva.

Entre los años 1943-1966 se produce la época de mayor esplendor de las minas de oro de Rodalquilar, comenzando con la llegada de la Empresa Nacional Adaro en junio de 1943 y acabando con el cierre de las minas en septiembre de 1966. Entre 1943 y 1956, Adaro retomará un esquema productivo muy similar al de la empresa Minas de Rodalquilar S. A., utilizando sus mismas instalaciones e infraestructuras mineras. Pero a partir de mayo de 1956 se producirá una auténtica revolución con la puesta en marcha de las nuevas minas del cerro del Cinto (las primeras a cielo abierto en la historia de Rodalquilar), con la inauguración de la nueva planta de cianuración Denver en el pueblo de Rodalquilar (la más grande de la Europa occidental por aquellos años), con la inauguración de las nuevas infraestructuras en el pueblo de Rodalquilar (poblado minero, garaje, economato, farmacia, con-

Instalación metalúrgica de cianuración, conocida como planta Denver y levantada por la Empresa Nacional Adaro en el año 1956 en el pueblo de Rodalquilar 
sultorio, iglesia, etc.) y con la inauguración de las nuevas infraestructuras del cerro del Cinto (pista para camiones, túnel, casa de motores, comedor, etc.) (HERNÁNDEZ ORTIZ, 2002: 181-186, 192-197). Entre 1943 y 1966 se extrajo aproximadamente el $75 \%$ de todo el oro registrado oficialmente en la historia de Rodalquilar (HERNÁNDEZ ORTIZ, 2002: 248-250). Las minas más destacadas de este periodo histórico fueron Transacción, Luisito de Oro, Consulta, Las Niñas; Ronda y el Resto, Cerro Colorado, María Josefa, San Diego y Socavón 340 (HERNÁNDEZ ORTIZ, 2002; 2008).

Entre los años 1989 y 1990 hubo una fugaz reapertura de las minas de oro del cerro del Cinto de Rodalquilar, liderada por la multinacional norteamericana St. Joe Transacción, pero la aventura duró poco y en 1990 se acabó definitivamente la historia de la minería en Rodalquilar.

\section{LAS OTRAS MINERÍAS DE RODALQUILAR}

En la historia de la minería de Rodalquilar han existido otros tipos de minas que no han llegado a alcanzar la relevancia de las minas de oro en el siglo $\mathrm{XX}$ o de las minas de alumbre en el siglo XVI.

En la segunda mitad del siglo XIX y la primera del XX, existieron en Rodalquilar diferentes canteras de adoquines para pavimentación y también para escolleras. Las principales canteras estaban localizadas en el cerro de Romero, en la Punta del Bergantín y en el cerro de Los Lobos. Los adoquines se labraban en la misma cantera y eran bajados hasta las vecinas playas del Playazo y del Carnaje (unas veces mediante cables aéreos y otras mediante animales) en donde eran embarcados (HERNÁNDEZ ORTIZ, 2004).

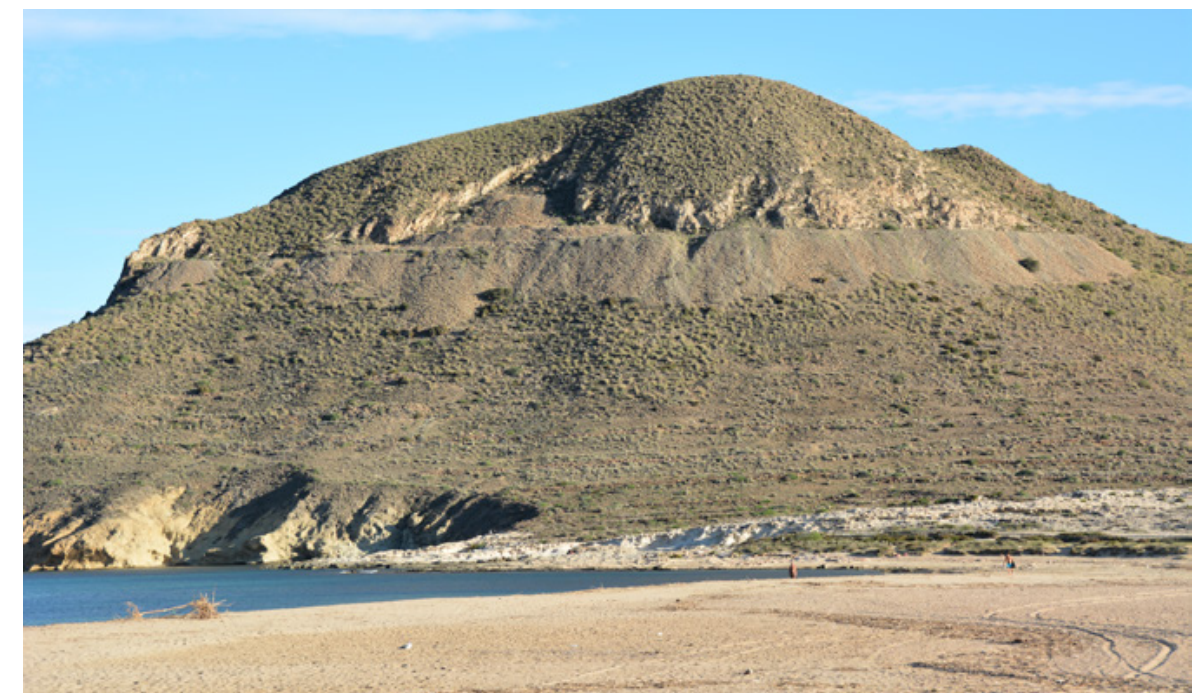


En la segunda mitad del siglo XIX y la primera del XX, existieron en Rodalquilar diferentes minas de caolines y también de otros minerales de la arcilla. $A$ excepción de los pozos de Teresa (situados en las inmediaciones del castillo de los Alumbres), las dimensiones de esas minas eran muy modestas, pero era lo suficiente para extraer el caolín que luego se utilizaba en alfarería principalmente (PUCHE RIART, 2002: 410; HERNÁNDEZ ORTIZ, 2002: 70-71).

En el último tramo del siglo XVIII existieron algunas minas que se dedicaban a extraer ágatas y amatistas que luego eran vendidas en diferentes puntos de España y Portugal. La zona en donde estaban enclavadas estas
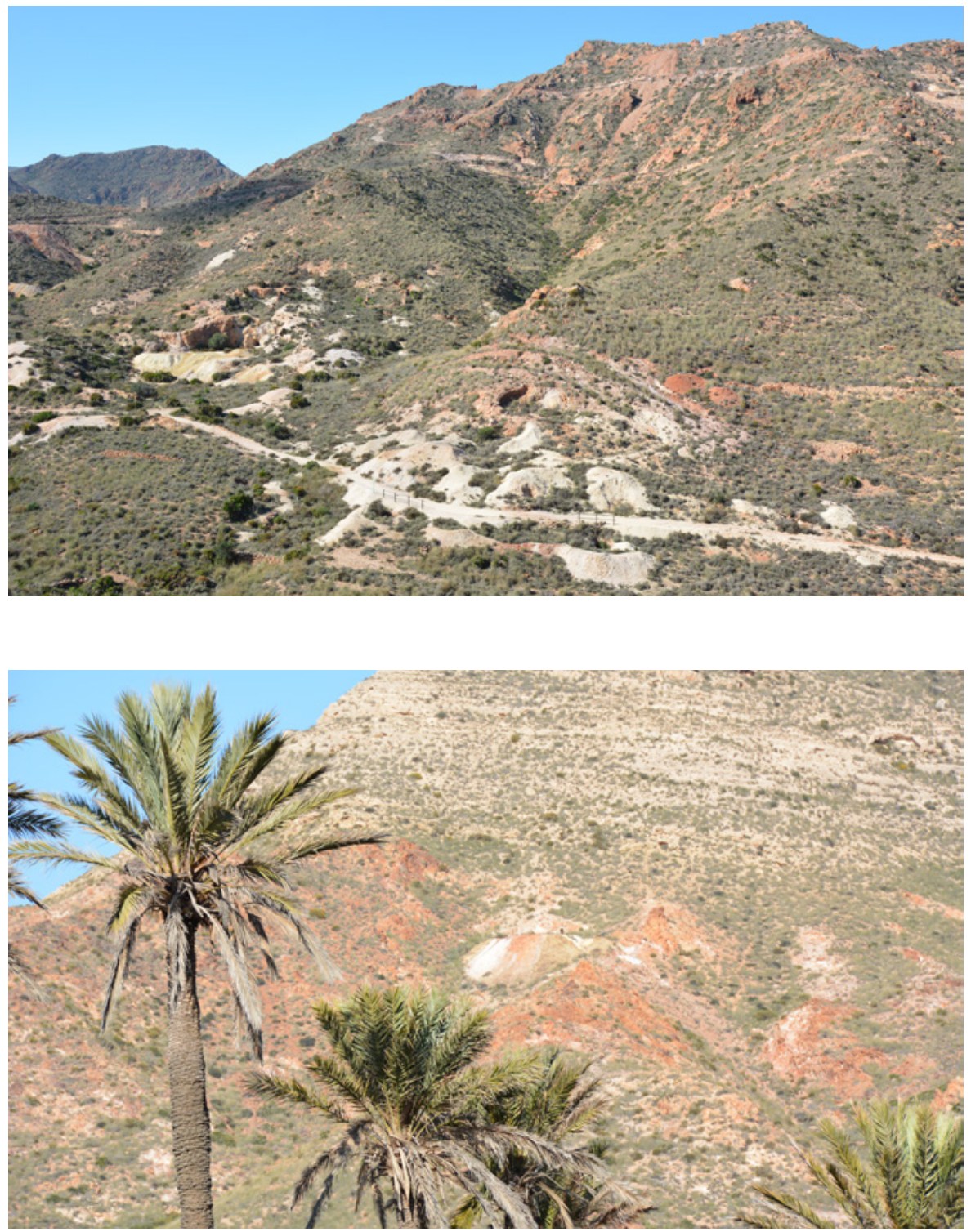

Pequeñas minas de caolines situadas al pie de la ladera este del cerro del Cinto

Pozos de Teresa en la ladera sur del cerro de La Molata. Probablemente es de estas minas de donde salieron los materiales refractarios que al parecer se explotaron en Rodalquilar a finales del siglo XIX 




Mapa de localización de las principales labores mineras de Rodalquilar. Se puede considerar que el grueso del patrimonio minero de Rodalquilar está compuesto por estas minas y por sus instalaciones auxiliares situadas en sus inmediaciones | fuente HERNÁNDEZ ORTIZ; PUCHE RIART; ANTICH CORTES, 2005: 663

explotaciones es en los alrededores del actual mirador de las Amatistas (GIL ALBARRACÍN, 2002; HERNÁNDEZ ORTIZ, 2009: 18).

\section{CONCLUSIONES}

El rico patrimonio geológico existente en Rodalquilar ha sido explotado económicamente a lo largo de los siglos mediante la minería y ha generado un rico patrimonio minero. Los afloramientos geológicos existentes y los restos mineros presentes sobre el terreno, junto con la documentación generada por las investigaciones desarrolladas en las últimas décadas sobre ambos patrimonios, son una base sólida para la puesta en valor de ellos y para intentar lograr un desarrollo económico sostenible en Rodalquilar, por ejemplo mediante el turismo activo o mediante el turismo cultural. 


\section{BIBLIOGRAFÍA}

- ARRIBAS, A. (1993) Mapa Geológico del distrito minero de Rodalquilar, Almería (1: 25.000). Madrid: Instituto Tecnológico Geominero de España, Secretaría General de la Energía y Recursos Minerales, MICYT, 1993

- ARRIBAS MORENO, A. (1998) El yacimiento epitermal de oro de Rodalquilar. Boletín Geológico y Minero, vol. 109, 5-6, pp. $15-28$

- ARRIBAS, A.; CUNNINGHAM, C.; RYTUBA, J.; RYE, R.; KELLY, W.; PODWYSOCKY, M.; MCKEE, E.; TOSDAL, R. (1995) Geology, Geochronology, Fluid Inclusions, and Isotope Geochemistry of the Rodalquilar Gold Alunite Deposit, Spain. Economic Geology, vol. 90, 1995, pp. 795822

- ARRIBAS PALAU, A. (1953) Una Necrópolis romana en Rodalquilar (Almería). Revista Ampurias, n. ${ }^{\circ}$ 15-16, septiembre 1953, pp. 365-369

- E.M.M.E. Estadística minera y metalúrgica de España (1861-1996) Resúmenes anuales de la provincia de Almería. Madrid: Consejo de Minería y Ministerio de Industria, 1861-1996

- FRANCO SILVA, A. (1996) El alumbre del Reino de Murcia. Una historia de ambición, intrigas, riqueza y poder. Murcia: Real Academia Alfonso X El Sabio, 1996 (Colección Biblioteca de estudios regionales, $n .^{\circ} 18$ )

- GILALBARRACÍN, A. (1995) Los castillos de Rodalquilar en el Parque Natural del Cabo de Gata-Níjar. Granada: Editorial G.B.G., 1995

- GIL ALBARRACín, A. (2002) Viaje al Cabo de Gata en 1805 por Simón de Rojas Clemente. Almería; Barcelona: G.B.G., 2002

- GUAL CAMARENA, M. (1976) Vocabulario del comercio medieval: colección de aranceles, aduaneros de la Corona de Aragón (siglos XIII y XIV). Barcelona: El Albir, 1976

- GUILLÉN RIQUELME, M. (1997) Mazarrón 1900. Murcia: Ayuntamiento de Mazarrón,1997

- HERNÁNDEZ ORTIZ, F. (2002) El oro y las minas de Rodalquilar. Años 1509-1990. Sevilla: Consejería de Medio Ambiente, 2002

- HERNÁNDEZ ORTIZ, F. (2004) Canteras de adoquines en Rodalquilar (Almería), en la primera mitad del siglo $\mathrm{XX}$. De Re Metallica. Sociedad Española Defensa del Patrimonio Geológico y Minero (SEDPGYM), n. ${ }^{\circ} 2$, segunda época, 2004, pp. 39-42

- HERNÁNDEZ ORTIZ, F. (2007) La minería en la Sierra del Cabo de Gata (Almería). De Re Metallica. Sociedad Española Defensa del Patrimonio Geológico y Minero (SEDPGYM), n. ${ }^{\circ}$ 8, segunda época, 2007, pp. 1-10

- heRNÁNDEZ ORTIZ, F. (2008) La minería del oro de
Rodalquilar durante el siglo XX: La estructura empresarial y su influencia en el éxito minero. Boletín Geológico y Minero, vol. 119, n. ${ }^{\circ}$ 3, julio-septiembre 2008, pp. 343-360

- HERNÁNDEZ ORTIZ, F. (2009a) Los alumbres de Rodalquilar. Las otras minas. Almería: Instituto de Estudios Almerienses, 2009

- HERNÁNDEZ ORTIZ, F. (2009b) Instalaciones Metalúrgicas Contemporáneas en la Sierra del Cabo de Gata (Almería). De Re Metallica. Sociedad Española Defensa del Patrimonio Geológico y Minero (SEDPGYM), n. ${ }^{\circ} 12$, segunda época, 2009, pp. 71-83

- HERNÁNDEZ ORTIZ, F. (2010) Factores en el auge y declive del alumbre español durante los siglos XV Y XVI. De Re Metallica. Sociedad Española Defensa del Patrimonio Geológico y Minero (SEDPGYM), n. ${ }^{\circ} 15$, segunda época, 2010, pp. 35-42

- HERNÁNDEZ ORTIZ, F.; PUCHE RIART, O.; ANTICH CORTES, N. (2005) Patrimonio Minero-Metalúrgico de Rodalquilar. Metodología de catalogación y resultados. En PUCHE RIART, O. (dir.) II Simposio sobre Minería y Metalurgia históricas en el Sudoeste europeo. Madrid, 24, 25 y 26 de junio de 2004. Madrid: Sociedad Española para la Defensa del Patrimonio Geológico y Minero, 2005, pp. 659-666

- La MINERÍA Andaluza (1986) Libro blanco. Tomo I. Sevilla: Dirección General de Industria, Energía y Minas, Consejería de Economía y Fomento, 1986

- LÓPEZ RUIZ, J.; RODRÍGUEZ BADIOLA, E. (1980) La región volcánica Neógena del Sureste de España. Estudios Geológicos, vol. 36, n. ${ }^{\circ} 1-2,1980$, pp. 5-64

- LÓPEZ SOLER, J. (1940) El oro de España en la Región de Cabo de Gata, Almería (manuscrito) Signatura 48405-1. Archivo Histórico Provincial de Almería

- MARTíN, J. M.; BRAGA, J. C.; BETZLER, C. (2003) Late Neogene-Recent uplift of the Cabo de Gata volcanic province, Almería, SE Spain. Geomorphology, vol. 50, issues 1-3, February 2003, pp. 27-42

- MUÑOZ BUENdíA, A. (2007) Los alumbres de Rodalquilar (Almería): sueños y fracasos de una gran empresa minera del siglo XVI. En ANDÚJAR CASTILLO, F.; DÍAZ LÓPEZ, J. P. (coord.) Los señoríos en la Andalucía Moderna. El Marquesado de los Vélez. Almería: Instituto de Estudios Almerienses, 2007, pp. 463-490 (Historia, Estudios monográficos, n. ${ }^{\circ}$ 14)

- PÉREZ DE PERCEVAL VERDE, M. A. (1989) La minería almeriense contemporánea (1800-1930). Almería: Zéjel, 1989

- PUCHE RIART, O.; MAZADIEgo MARTÍNEZ, L. F.; FERNÁNDEZ GUTIÉRREZ DEL ÁLAMO, L. J. (2002) 
Fabricación de ladrillos refractarios en Valdemorillo (Madrid): Minas y fábrica de D. Ángel González. En BRANDAO, J. M. (coord.) Actas do Congresso Internacional sobre Patrimonio Geológico e Mineiro (Beja, 4 al 7 de octubre de 2001). Lisboa: Museu do Instituto Geológico e Mineiro, 2002, 409-416

- REVISTA Minera, Metalúrgica y de Ingeniería. Serie C. Tomo I. Madrid: [s.n.], 1883

- RUIZ MARTín, F. (2005) Los alumbres españoles. Un índice de la coyuntura económica europea en el siglo XVI. Madrid: Fundación Española de Historia Moderna; Pareja (Guadalajara): Bornova, 2005

- SÁNCHEZ PICÓN, A. (2015) La quimera del oro. Visionarios locales, negocio privado e inversión pública en unas minas del sureste de España (Rodalquilar, 18831966). Revista de Historia Industrial, n. ${ }^{\circ}$ 58. Año XXIV. Número especial. Homenaje a Antonio Parejo, 2015, pp. 287-318 